\title{
Experimental research on novel oil displacement and profile control system for heterogeneous reservoir
}

\author{
Peng Lv ${ }^{1} \cdot$ Yigang Liu $^{1} \cdot$ Yunbao Zhang ${ }^{1} \cdot$ Yanyue $\mathrm{Li}^{1} \cdot$ Huan Xia ${ }^{1}$
}

Received: 19 March 2019 / Accepted: 17 August 2019 / Published online: 22 August 2019

(c) The Author(s) 2019

\begin{abstract}
Polymer flooding and surfactant/polymer flooding (SP flooding) were mainly focused on the improvement in oil-water flow ratio and the reduction in oil-water interfacial tension. Preformed particle gel (PPG) flooding was mainly focused on the reservoir heterogeneity improvement. Each of these technologies has its own limitations. Heterogeneous system flooding (HS-PP flooding) was proposed as a novel flooding method aimed to improve oil-water flow ratio and reservoir heterogeneity at the same time. The HS-PP flooding system was composed of PPG and polymer solution. HS-PP flooding, polymer flooding and SP flooding as different chemical EOR methods were studied in laboratory in physical simulation heterogeneous model. Property of cubic expansion of PPG was researched by laser particle analyzer. The result shows that cubic expansion of PPG in simulation water is obvious and can be controlled. The effect of PPG on the diversion rate modification in double parallel sandstone model was obvious. The oil displacement experiments of the three different flooding systems with the same viscosity in physical simulation heterogeneous model were studied. The results show that the HS-PP flooding improves the oil recovery by $20.04 \%$, comparing the result of $12.67 \%$ for polymer flooding and $16.66 \%$ for SP flooding, respectively. HS-PP flooding as a novel flooding method shows an excellent ability for stabilizing oil production and controlling water cut. The mechanism of the HS-PP flooding was discussed briefly. In addition to the viscoelastic displacement of polymers, the special circulation ability of "accumulating-deforming (collapsing)-accumulating again" of PPG is the main reason why the HS-PP flooding shows an excellent property for stabilizing oil production and controlling water cut.
\end{abstract}

Keywords Heterogeneous reservoir $\cdot$ Heterogeneous system flooding $\cdot$ Preformed particle gel $\cdot$ Profile control $\cdot$ Enhanced oil recovery

\section{Introduction}

As most of the major oil fields in China have entered high water cut stage, technology having the characteristics of stabilizing oil production and controlling water cut has become increasingly important (Willhite and Pancake 2008; He et al. 2009; Wei (2013); Hendraningrat and Zhang 2015; Li et al. 2015). Polymer flooding and polymer/surfactant flooding (SP flooding) are currently the most widely used chemical flooding technologies (Shah and Schechter 1977; Needham and Doe 1987). In principle, the two technologies increase the swept volume and improve the displacement efficiency mainly by increasing water phase viscosity and reducing the

Peng Lv

hilvp@163.com

1 Tianjin Branch of CNOOC (China) Ltd., Haichuang Street 2121, Tanggu, Tianjin 300452, China interfacial tension between oil and water phases (Prabir and Paşaoğlu 2004; Amaloei and Kharrat 2009; Yu et al. 2010). The applicability of the two widely used chemical flooding technologies in the heterogeneous reservoir is very poor. New technology for improving oil recovery in heterogeneous reservoir is of great significance. PPG flooding and synergistic system containing PPG featuring in excellent ability of stabilizing oil production and controlling water cut has attracted extensive interest recently (Cui 2011; Cao 2013; Zhang et al. 2014; Goudarzi et al. 2014; Chenet al. 2017; Zhao et al. 2018; Lenji et al. 2018; Liu et al. 2018). In this flooding system, PPG was mainly used for reservoir microstructure improvement. In this paper, HS-PP system composed of preformed particle gel and polymer solution was proposed as a novel flooding method aimed to improve oil-water flow ratio and reservoir heterogeneity at the same time. Property of cubic expansion and plugging property of PPG were researched in this paper. HS-PP flooding, polymer flooding and SP flooding as different 
chemical EOR methods were studied in laboratory in physical simulation heterogeneous model. The mechanism of the HS-PP flooding was discussed briefly. This paper is helpful for practical application of HS-PP flooding in oil field.

\section{Experimental apparatus and materials}

\section{Experimental apparatus}

The apparatus included viscometer (Brookfield DV-II), interfacial tension apparatus (TX-500C), laser particle analyzer (Mastersizer 3000), displacement equipment (pressure gauge, thermostat, physical simulation counter-rhythm model), $\mathrm{PH}$ meter, etc.

\section{Experimental materials}

The chemicals applied in the experiments, such as $\mathrm{NaOH}$ ( $\geq 99.5 \%), \mathrm{Na}_{2} \mathrm{CO}_{3}(\geq 99.5 \%) \mathrm{NaCl}(>99.5 \%), \mathrm{CaCl}_{2}(>96 \%)$ and $\mathrm{MgCl}_{2} \cdot 6 \mathrm{H}_{2} \mathrm{O}(>99 \%)$, were provided by Beijing Modern East Fine Chemical Co. The viscosity of the crude oil applied in the experiments was $17.46 \mathrm{mPa}$ s at $57^{\circ} \mathrm{C}$. The ion composition of simulation water is shown in Table 1.

Polymer A with solid content of $90 \%$ and molecular weight of 15 million, surfactant B with solid content of $30 \%$ and PPG $C$ with diameter of 300-600 $\mu \mathrm{m}$ and solid content of $86 \%$ were used for preparing the different flooding system. Double parallel sandstone model $(\Phi 2.5 \times 10 \mathrm{~cm})$ with $2000 \mathrm{mD}$ and $500 \mathrm{mD}$ and physical simulation counterrhythm model $(30 \times$ $4.5 \times 4.5 \mathrm{~cm}$ ) combined of 3 vertical layers with $2000 \mathrm{mD}$, $800 \mathrm{mD}$ and $100 \mathrm{mD}$ were used for displacement experiment.

\section{Experiments}

\section{Volume-expanding experiments of PPG}

The measurement steps of particle size distribution of PPG before/after expanding by the laser particle analyzer are as follows:

1. Turn on the power supply according to the order of the laser particle analyzer, computer and printer, and fill the sample table with distilled water, turn on the pump and preheat the instrument for $10 \mathrm{~min}$. Enter the operation procedure of the laser particle analyzer, establish the connection and then set the corresponding parameters.

2. After the series work of compensation measurement, optical path correction and blank measurement have been completed, according to the prompt of the software, the PPG sample with a certain dissolution time is added to the sample table as an appropriate concentration, and then the particle size analysis test is carried out.

3. Make parallel experiments, preserve the results and print the report according to the requirements.

4. Exit the procedure, turn off the power supply and fill the sample table with distilled water again to prevent residual particles from attaching to the lens.

\section{Plugging properties of PPG}

Take the double parallel sandstone model to study the plugging performance of PPG. According to the value of permeability, the two different permeability cores were marked as the low-permeability layer (LPL) and the high-permeability layer (HPL). The simulated water was injected at the rate of $0.4 \mathrm{~mL} / \mathrm{min}$. The diversion rate of different layers was calculated. When the diversion rate was stable, the PPG solution $(400 \mathrm{mg} / \mathrm{L})$ was injected for $0.8 \mathrm{Pv}$ at the rate of $0.4 \mathrm{~mL} / \mathrm{min}$. And then the simulated water was re-injected at the rate of $0.4 \mathrm{~mL} / \mathrm{min}$. The diversion rates at different stages for each layer were calculated.

\section{IFT measurement for SP system}

The IFT between SP solution and crude oil was measured by spinning drop interfacial tensiometer TX-500C at $57{ }^{\circ} \mathrm{C}$. A drop of oil was maintained horizontally by a microsyringe in a quartz cuvette tube which was full of SP solution (polymer $1500 \mathrm{mg} / \mathrm{L}$; surfactant B $1000 \mathrm{mg} / \mathrm{L}$ ). The tube was rotated at a high speed of $6000 \mathrm{r} / \mathrm{min}$ under the action of the instrument. A charge-coupled device (CCD) camera captured the oil drop profile in the solution in real time and transferred data, and then the data were digitized and analyzed by software. IFT was directly calculated by employing the Laplace equation.

\section{Viscosity measurement for different flooding systems}

Measurement of viscosity was performed using a brinell viscometer DV-II. The polymer solution (polymer concentration $1500 \mathrm{mg} / \mathrm{L}$ ), SP solution (polymer concentration $1500 \mathrm{mg} / \mathrm{L}$; surfactant B concentration $1000 \mathrm{mg} / \mathrm{L}$ ) and HP-PP solution (polymer concentration $1500 \mathrm{mg} / \mathrm{L}$; PPG concentration $400 \mathrm{mg} / \mathrm{L}$ ) viscosities were measured by brinell viscometer at $57^{\circ} \mathrm{C}$. Each sample was stirred at a speed of $250 \mathrm{r} / \mathrm{min}$ for 5 min in a $57^{\circ} \mathrm{C}$ water bath before measurement.
Table 1 Ion composition of the simulation water

\begin{tabular}{llllllllll}
\hline Ions & $\mathrm{Na}^{+}+\mathrm{K}^{+}$ & $\mathrm{Mg}^{2+}$ & $\mathrm{Ca}^{2+}$ & $\mathrm{Cl}^{-}$ & $\mathrm{SO}_{4}{ }^{2-}$ & $\mathrm{HCO}_{3}{ }^{-}$ & $\mathrm{CO}_{3}{ }^{2-}$ & Total & $\mathrm{pH}$ at $25^{\circ} \mathrm{C}$ \\
\hline $\mathrm{C}(\mathrm{mg} / \mathrm{L})$ & 986.1 & 16.2 & 39.5 & 742.4 & 495.2 & 911.2 & 0 & 3190.6 & 8.2 \\
\hline
\end{tabular}




\section{Displacement experiment}

Flooding effect for different flooding systems was evaluated by displacement experiment in physical simulation model.

The displacement procedure is as follows:

1. The model is saturated with simulation water in a vacuum state. So the pore volume is calculated by the water volume.

2. The model is flooded by the crude oil until no more water could be displaced. The oil saturation is calculated by the ratio of saturation oil volume to the saturation water volume in step 1.

3. The model is flooded by simulation water at a rate of $0.4 \mathrm{ml} / \mathrm{min}$. When water cut reaches $98 \%$, the model is flooded by one of flooding systems. When the injected flooding system volume reaches $0.5 \mathrm{PV}$, the model is flooded by simulation water again until no more oil could be displaced.

\section{Results and discussion}

\section{Volume-expanding results of PPG}

Expanding properties of PPG particles in the simulation water with the dissolution time were studied by the laser particle analyzer. PPG particle size and its cubic expanding results in simulation water with dissolution time at $57^{\circ} \mathrm{C}$ are shown in Table 2.

The initial value of $D_{50}$ is $442 \mu \mathrm{m}$. The value of $D_{50}$ is 2.9 times of the initial value when the PPG is dissolved in the simulation water for 7 days. The value of $D_{50}$ is 3.4 times of the initial value when the PPG is dissolved in the simulation water for 15 days. The result shows that the volume of PPG is expanded with the dissolution time and the expanding rate decreases after 7 days. The PPG particle size tends to be stable after 15 days. As the conclusion of Liu et al. (2018) about the expansion property of B-PPG, the cubic expansion of PPG in simulation water is obvious and finite. It satisfies

Table 2 PPG particle size and its cubic expanding results at $57^{\circ} \mathrm{C}$

\begin{tabular}{lllll}
\hline Sample & $\begin{array}{l}\text { Dissolution } \\
\text { time (days) }\end{array}$ & $D_{10}(\mu \mathrm{m})$ & $D_{50}(\mu \mathrm{m})$ & $D_{90}(\mu \mathrm{m})$ \\
\hline PPG & 0 & 274 & 442 & 690 \\
& 1 & 374 & 1430 & 2560 \\
& 5 & 409 & 1290 & 2480 \\
& 7 & 430 & 1150 & 2370 \\
& 10 & 467 & 1490 & 2610 \\
& 15 & 482 & 1512 & 2635 \\
& 30 & 480 & 1510 & 2632 \\
\hline
\end{tabular}

the requirements of the heterogeneous system displacement. Expansion and insolubility of PPG in solution are the prerequisite for profile controlling.

\section{Plugging results of PPG solution}

The plugging results of PPG solution in the double parallel sandstone model are shown in Fig. 1.

It can be seen from Fig. 1 that the effect of PPG on the diversion rate modification was obvious. After injecting $0.6 \mathrm{Pv}$ simulation water, the distribution rate of low-permeability layer and high-permeability layer was $8 \%$ and $92 \%$, respectively. The diversion rate of high-permeability layer decreased rapidly after the injection of PPG solution. After injecting $0.5 \mathrm{Pv}$ follow-up simulation water, the distribution rate of low-permeability layer and high-permeability layer was $54 \%$ and $46 \%$, respectively. The distribution rate of the high-permeability layer and the low-permeability layer has been effectively adjusted.

\section{Displacement experiment of the three different flooding systems}

The IFT between SP system and oil, the viscosities of different flooding system and the displacement experiment results are shown in Table 3.

All sorts of conditions including model porosity, oil saturation and viscosity of flooding system were very close. HS-PP flooding, SP flooding and polymer flooding show different effects from the view of the improved recovery. Based on the same recovery of water flooding (about 29\%), oil recovery enhanced by HS-PP flooding was $20.04 \%$ compared with $12.67 \%$ by polymer flooding and $16.66 \%$ by SP flooding, respectively. HS-PP flooding shows better oil displacement effect than polymer flooding and SP flooding.

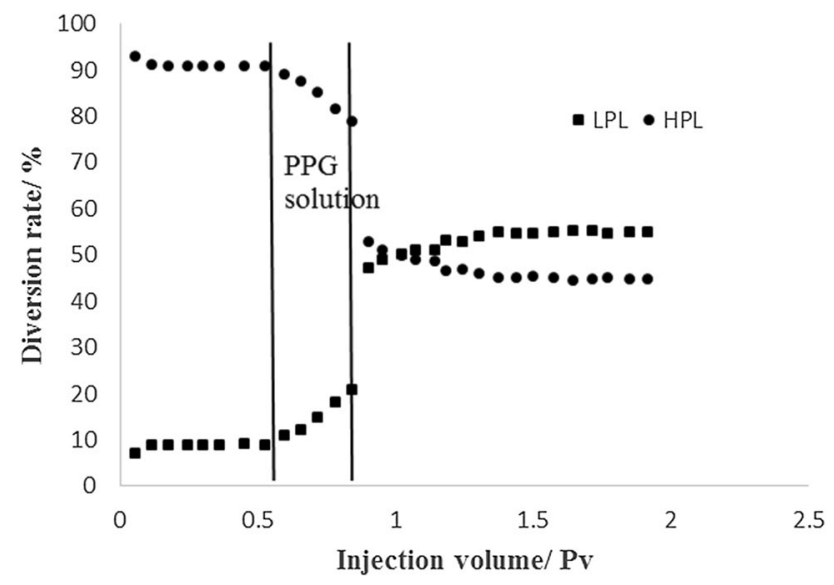

Fig. 1 The result of plugging properties of PPG in the double parallel sandstone model 
Table 3 Properties of the different flooding systems and displacement experiment results

\begin{tabular}{lllllll}
\hline Flooding system & $\begin{array}{l}\text { Model } \\
\text { porosity } \\
(\%)\end{array}$ & $\mathrm{S}_{\mathrm{io}} / \%$ & $\mathrm{c} / \mu / \sigma$ & $\begin{array}{l}\text { Oil recovery } \\
\text { by water }(\%)\end{array}$ & $\begin{array}{l}\text { EOR (\%) } \\
\text { Ultimate } \\
\text { recovery } \\
(\%)\end{array}$ \\
\hline Polymer flooding & 25.72 & 71.61 & $\begin{array}{l}\text { Polymer } \\
(1500) / 11.6 /-\end{array}$ & 28.65 & 12.67 & 41.32 \\
SP flooding & 26.77 & 73.76 & $\begin{array}{l}\text { Polymer/surfactant } \\
(1500 / 1000) / 11.1 / 0.012\end{array}$ & 30.08 & 16.66 & 46.74 \\
HP-PP flooding & 26.36 & 71.68 & $\begin{array}{l}\text { Polymer/PPG } \\
(1250 / 400) / 11.7 /-\end{array}$ & 29.06 & 20.04 & 49.1 \\
\hline
\end{tabular}

Remarks: $S_{\text {io }}$-initial oil saturation; EOR - enhanced oil recovery; $c$-concentration of flooding system, $\mathrm{mg} / \mathrm{L} ; \mu$-viscosity of flooding system, $\mathrm{mPa} \mathrm{s} ; \sigma$-interfacial tension between flooding system and oil, $\mathrm{mN} / \mathrm{m}$

\section{Mechanism of HS-PP flooding}

Heterogeneous system is composed of polymer solution and PPG particles. It is a solid-liquid coexistence system. As a continuous phase, polymer solution not only play the role in conventional polymer flooding, but also carry the PPG particles as a dispersed phase into the reservoir. In the actual displacement progress, expanded PPG particles were injected into the model with the flooding system. The large pore path formed in the water flooding progress would be the preferred path of injected HS-PP flooding system. The expanded PPG particles resided in the macroscopic throats forming "accumulation" and blocked the large pore path making the subsequent displacement HS-PP system change the flow direction. The "accumulation" deformed or collapsed under a higher drive force, and they formed "accumulation" again when the force was small in the larger pore throats or channels. The special circulation ability of "accumulating-deforming (collapsing)-accumulating again" promotes their deep migration improving the heterogeneity of the physical model. Zhao et al. (2018) studied the restarting pressure gradient for preformed particle gel passing through pore-throat. Their research provided a way to evaluate the process of "plugging-deformation-restarting" for PPG passing through the pore-throat. They validated our hypothesis about the mechanism of PPG from microcosmic experiment. It is the reason why the HS-PP flooding shows an excellent ability for stabilizing oil production and controlling water cut.

Figure 2 shows the pressure change with injected volume of different flooding systems. In the subsequent water flooding stage, pressure drop rate for HS-PP flooding is the slowest. It also illustrates that the PPG particles can continuously deform and migrate in the model and have long-lasting profile adjustment ability.

Figure 3 shows the water cut change with injected volume of different flooding systems.

The water cut was greatly reduced by HS-PP flooding. Experimental phenomena and displacement mechanism

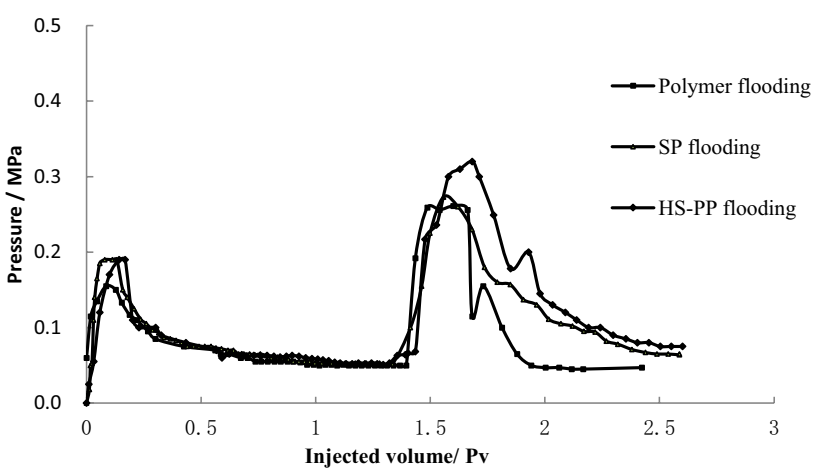

Fig. 2 Pressure change in displacement experiment in model

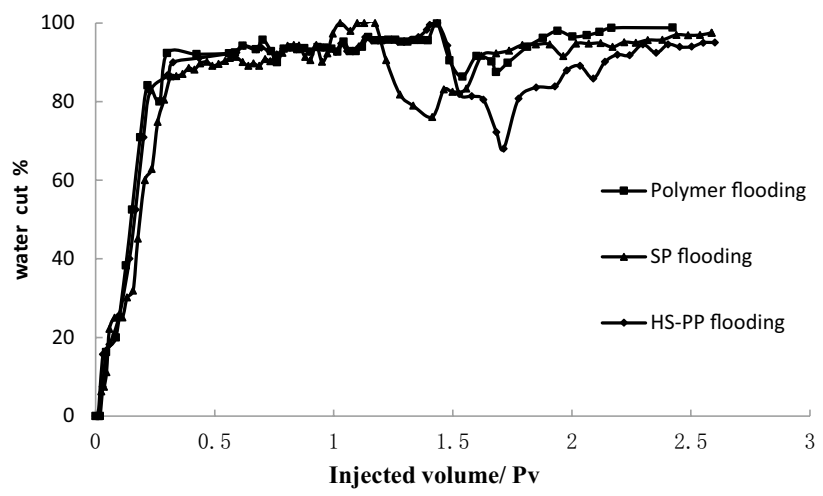

Fig. 3 Water cut in displacement experiment in model

are corresponding to each other. Relative to the water cut of water flooding, the maximum decrease in water cut after flooding HS-PP is $32 \%$. The result is similar to the result of Lenji et al. (2018). Their results show that PPG was able to reduce water production by $30-65 \%$. 


\section{Conclusion}

1. The volume of PPG is expanded with the dissolution time, and the expanding rate decreases after 7 days. The PPG particle size tends to be stable after 15 days.

2. HS-PP flooding, SP flooding and polymer flooding show different effects from the view of the improved recovery. Based on the same recovery of water flooding, oil recovery enhanced by HS-PP flooding was larger than the ones by polymer flooding and SP flooding.

3. In addition to the viscoelastic displacement of polymers, the special circulation ability of "accumulating-deforming (collapsing)-accumulating again" of PPG promotes their deep migration improving the heterogeneity of the physical model. It is the main reason why the HS-PP flooding shows an excellent property for stabilizing oil production and controlling water cut.

Open Access This article is distributed under the terms of the Creative Commons Attribution 4.0 International License (http://creativeco mmons.org/licenses/by/4.0/), which permits unrestricted use, distribution, and reproduction in any medium, provided you give appropriate credit to the original author(s) and the source, provide a link to the Creative Commons license, and indicate if changes were made.

\section{References}

Cao XL (2013) Design and performance evaluation on the heterogeneous combination flooding system. Pet Process Sect 29(1):115-121

Chen X, Feng Q, Wei L, Sepehrnoori K (2017) Modeling preformed particle gel surfactant combined flooding for enhanced oil recovery after polymer flooding. Fuel 194:42-49

Cui XH (2011) A study on the heterogeneous combination flooding system. Acta Petr Sin 32(1):122-126

Goudarzi A, Zhang H, Varavei A et al (2014) A laboratory and simulation study of preformed particle gels for water conformance control. Fuel 140:502-513
He Y, Xiong S, Yang Z et al (2009) The research on cross-linking polymer gel as in-depth profile control agent. Pet Sci Technol 27(12):1300-1311

Hendraningrat L, Zhang J (2015) Polymeric nanospheres as a displacement fluid in enhanced oil recovery. Appl Nanosci 5(8):1009-1016

Jamaloei BY, Kharrat R (2009) Fundamental study of pore morphology effect in low tension polymer flooding or polymer-assisted dilute surfactant flooding. Transp Porous Media 76(2):199-218

Lenji MA, Haghshenasfard M, Sefti MV et al (2018) Experimental study of swelling and rheological behavior of preformed particle gel used in water shutoff treatment. J Pet Sci Eng 169:739-747

Li CF, Li Y, Li XM et al (2015) The application of microbial enhanced oil recovery technology in Shengli oilfield. Pet Sci Technol 33:556-560

Liu YG, Ding MC, Han YG et al (2018) Migration and profile control properties of B-PPG in oil reservoirs. Oil Drill Prod Technol 03:393-399

Needham R, Doe P (1987) Polymer flooding review J Pet Technol 39(12):1503-1507

Prabir D, Paşaoğlu GG (2004) An optimal viscosity profile in enhanced oil recovery by polymer flooding. Int J Eng Sci 42:2029-2039

Shah DO, Schechter RS (1977) Improved oil recovery by surfactant and polymer flooding. Academic Press, New York

Wei J (2013) Evaluation of the gel profile control agent polyacrylamide in enhanced oil recovery. Adv Pet Explor Dev 5(1):100-105

Willhite GP, Pancake RE (2008) Controlling water production using gelled polymer systems. SPE Reserv Eval Eng 11(3):454-465

Yu Q, Jiang H, Zhao C (2010) Study of interfacial tension between oil and surfactant polymer flooding. Pet Sci Technol 28(18):1846-1854

Zhang L, Liu H, Cheng X (2014) Field test of PPG/polymer/surfactant flooding after polymer flooding. J Northeast Pet Univ 38(1):63-68

Zhao W, Liu H, Wang J et al (2018) Investigation of restarting pressure gradient for preformed particle gel passing through pore-throat. J Petrol Sci Eng 168:71-80

Publisher's Note Springer Nature remains neutral with regard to jurisdictional claims in published maps and institutional affiliations. 